\title{
LA EVOLUCIÓN DE LA TEORÍA DEL FUROR POÉTICO EN EL NEOPLATONISMO RENACENTISTA: LA GENIAL RELECTURA DE GIORDANO BRUNO EN DE GLI EROICI FURORI (1585)
}

\author{
DANIEL ORTIZ PEREIRA \\ Universidad Pontificia Comillas
}

\begin{abstract}
RESUMEN: La teoría ficiniana de los furores dio lugar a uno de los debates fundamentales en el seno de las corrientes filosóficas neoplatónicas de los siglos XV y XVI, que se centró en el análisis de la naturaleza, las funciones y los atributos del poeta. Esta cuestión era especialmente significativa a la hora de dotar de completitud a dos de los elementos centrales del sistema de Ficino: la teoría de la catarsis y el postulado de la inmortalidad del alma. Esto generó, en consecuencia, un paradigma estético concordante con la verticalidad de la antropología neoplatónica, que, sin embargo, desdeñaba per se la creación de una poética en sentido estricto. Conforme la metafísica neoplatónica se fue dispersando y transformando a lo largo del Tardorrenacimiento, Giordano Bruno se percató, a partir de una relectura de los textos ficinianos sobre el furor en su obra de 1585 De gli eroici furori, de ciertas inconsistencias incompatibles con una sensibilidad artística y literaria incipiente, creando así un nuevo modelo estético integral. El análisis de esta evolución será el objeto central de este artículo.
\end{abstract}

PALABRAS CLAVE: furor; estética; Giordano Bruno; Marsilio Ficino; neoplatonismo renacentista.

\section{The evolution of the theory of poetic frenzy in Renaissance neoplatonism: The genius re-reading of Bruno's De gli eroici furori (1585)}

ABSTRACT: The Ficinian theory of the frenzies gave rise to one of the main debates within Neoplatonic philosophical currents of the 15th and 16th centuries, which rested upon the analysis of the nature, the functions and the attributes of the poet. This issue was especially significant to the coherent completion of two of the main elements of Ficino's system: the theory of catharsis and the postulate of the immortality of the soul. This generated, as a consequence, an aesthetic paradigm concordant with the vertical condition of Neoplatonic anthropology, which, on the other hand, refused to create, strictly speaking, a subsequent theory of poetics. As Neoplatonic metaphysics were dispersed and transformed during the Late Renaissance, Giordano Bruno noticed, through a re-reading of the Ficinian texts on frenzy in his 1585 work De gli eroici furori, certain inconsistencies impossible to adapt to an emerging artistic and literary sensitivity, thus creating a new integral aesthetic model. The analysis of this evolution is to be the key point in this paper.

KEY WORDS: aesthetics; frenzy; Giordano Bruno; Marsilio Ficino; Renaissance neoplatonism.

1. INTRODUCCIÓN. LOS PARADIGMAS ESTÉTICOS EN LA OBRA DE FiCINO: TEORÍAS Y PROBLEMÁTICAS DEL FUROR POÉTICO

Como bien señala Wouter Hanegraaf en su artículo sobre los furores platónicos, una de las problemáticas esenciales a las que tuvo que enfrentarse el Renacimiento a la hora de interpretar los estados extáticos que había delineado Platón tanto en el Ión como en el Fedro con el término « $\mu \alpha v i ́ \alpha »$ era hasta qué punto dicho 
término, con amplias connotaciones negativas en todas sus variantes fuera del espectro platónico, podía identificarse con lo que la escuela florentina de Marsilio Ficino (1433-1499) tradujo por el término «furor», refiriéndose con este último a un estado de entusiasmo divino que traspasaba los límites de todo conocimiento sensible o racional y permitía una unión casi mística del alma con Dios ${ }^{1}$. En este sentido, aplicado al ámbito de la psicología artística, y en concreto a la poesía, este concepto reconocía la imposibilidad por parte del rapsoda de proferir sentencias de tal belleza sin estar, de un modo u otro, «en» la divinidad, esto es, poseído por ésta. Este fue, junto con el episodio de la expulsión de las Musas en la República, el gran alegato de Platón al reconocimiento de los poetas como instrumentos de los dioses y meros receptáculos pasivos de su influjo, con el que éstos pretendían demostrar ser los verdaderos autores de tan prodigiosos dichos y palabras ${ }^{2}$. Sin embargo, a partir de la producción de Plotino y de las corrientes neoplatónicas tardías, elaboradas mayormente desde una base mística y teúrgica (y cuyos máximos representantes fueron Proclo y Jámblico), el enriquecimiento de la jerarquía ontológica en el universo favoreció la ampliación de la inspiración artística a nuevos dominios, entre ellos el ámbito propiamente intelectual de la unio mystica, que dio

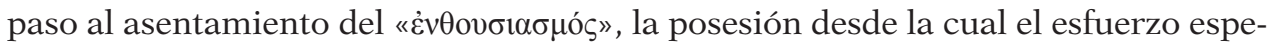
culativo no quedaba en cierto modo destituido (como propugnaba el ideal de poeta platónico), sino que, gracias a aquella, se elevaba y coronaba hasta su último fin, la contemplación del Uno. Así, el rapto místico solo se producía una vez llegado a la cumbre de la última hipóstasis, donde el furor divino permitía, con la consecuente intervención del verdadero éxtasis poético, (y en algunos casos musical), la unión y fusión definitiva ${ }^{3}$. Este progresivo equilibrio iniciado por Plotino y que el neoplatonismo tardío efectuó, a expensas de Platón, en cuanto a la intervención del sujeto contemplativo en el proceso de posesión favoreció que se dotase a la poesía, como

1 HanegraAf, W., «The Platonic Frenzies in Marsilio Ficino» en: DiJKstra, J. et al. (ed.): Myths, Martyrs and Modernity. Studies in the History of Religions in Honour of Jan N. Bremmer, Brill, 2010, pp. 554 y ss.

2 La expulsión de los poetas de la ciudad ideal en la República es otro de los grandes episodios contradictorios que caracterizan la producción estética de Platón, y que los neoplatónicos utlizaron posteriormente para alegorizar los dos tipos de genio poético presentes en el alma: el representado por los versos débiles y consolatorios (que pertenece al ámbito de lo sensible y debe ser, por tanto, erradicado) y aquel que, profiriendo graves y elevadas palabras, favorece la contemplación y el ascenso del alma a través de la belleza intelectual. Esto fue reflejado eminentemente por Boecio en la Consolatio Philosophiae a partir de la expulsión de las Musas y la elevación de los versos y cantos intelectuales. Para el desarrollo de la cuestión, véase: Ortiz Pereira, D., «Poesía y música en La consolación de la filosofía de Boecio», en: Revista Española de Filosofía Medieval, N 24, 2017, pp. 35-53.

3 Dodds, E. R., Pagan and Christian in an Age of Anxiety: Some Aspects of Religious Experience from Marcus Aurelius to Constantine, Cambridge University Press, 1965, p. 70. Cf. Sheppard, A., Studies on the Fifth and Sixth Essays on Proclus' Commentary on the Re-

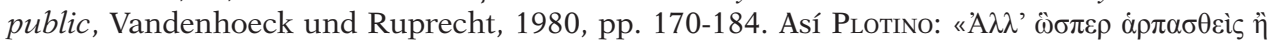

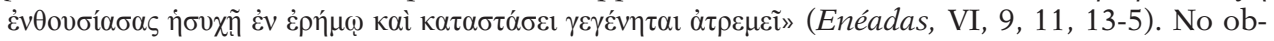
stante, ello no hizo a la poesía perder el carácter profético que ya le había dado Platón y que se mantendría a lo largo de todo el neoplatonismo renacentista. 
participante del furor divino, de un nuevo y radical espacio dentro del estudio de la psicología del alma en el ascenso noético.

La evolución y en cierto modo contraposición de estos dos modos de entender el furor poético fue el rasgo fundamental que recogió Ficino a la hora de inscribir esta cuestión dentro del sistema neoplatónico de la Academia Florentina, y así lo reflejó en el propio devenir de sus escritos al respecto, desde la prematura epístola De divino furore (1457), pasando por el De amore (1469) hasta culminar en los In Phaedrum commentaria (en torno a 1490). Así, desde la temprana adscripción a las genuinas tesis platónicas se irá paulatinamente entreviendo una mayor y más profunda comprensión de la reciprocidad entre el alma del artista inspirado (y consecuentemente de su creación) y el arrebato místico del sujeto poseído por la divinidad, lo que delimitará las propias semillas del Manierismo, en cuya antesala parece situarse Ficino en varios momentos ${ }^{4}$.

Esta evolución bien puede tomarse como el producto del propio énfasis de Ficino por resolver otra de las aparentes problemáticas que el propio Platón no terminó de poner en claro, y era justamente si, como don de las Musas, el furor poético podía considerarse autónomo en relación al furor más global que comprendía tanto la

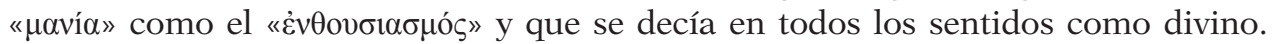
¿Era la poesía un rapto más del alma o estaba dotada de una naturaleza privilegiada? Y dado que Platón nunca terminó por estratificar sus postulados, la sistematización que Ficino trató de realizar de la teoría de los furores le llevó a establecer en sus múltiples comentarios hasta tres clasificaciones distintas en cuanto a su jerarquía: la del In Ionem, donde la locura poética se sitúa al comienzo, (y que Ficino recuperaría en el De amore), la del In Phaedrum ${ }^{5}$, en el que la poesía es el último estadio antes de la fusión amorosa, y por tanto ocupa el tercer lugar, y finalmente la del De divino furore y la tardía epístola a Pedro Divicio (fechada en 1491), donde la poesía se presenta en el segundo estadio, junto al furor amoroso ${ }^{6}$. A excepción del Ión (y

4 La progresiva importancia que fue adquiriendo el papel de la inspiración como parte activa del artista dotado de cualidades subjetivas dignas de exaltación fue uno de los principios fundamentales que el Manierismo tomó de las doctrinas ficinianas; así mismo, esto permitió revisar el concepto de "genio» bajo estos nuevos postulados. Como introducción a la cuestión, véase: Chastel, A., Marsile Ficin et L'Art, Droz, 1996, p. 57. Cf. E. Panofsky: Idea, Cátedra, 1989, pp. 52 y 90.

5 No debe confundirse el comentario principal de Ficino al Fedro (referido aquí como In Phaedrum y parte de su proyecto inicial de la década de 1460 de traducción de los diálogos platónicos) con los addenda que realizó a su propio comentario en torno a 1490, y que dedicó en una epístola a Julián de Médicis. Cuando nos refiramos a estos añadidos, lo haremos bajo el nombre de In Phaedrum commentaria et argumenta.

6 El estudio de las distintas clasificaciones de los furores por parte de Ficino ha sido ampliamente tratado por Allen, M. J., The Platonism of Marsilio Ficino. A Study of his Phaedrus Commentary, its Sources and Genesis, University of California Press, 1984, pp. 4748. La hipótesis clásica respecto a por qué las distintas clasificaciones se suele atribuir a A. SHEPPARD, «The Influence of Hermias on Marsilio Ficino's Doctrine of Inspiration» en: Journal of the Warburg and Courtauld Institutes, $\mathrm{N}^{\circ} 43,1980$, p. 101. (pp. 97-109), que afirma que se debe a la lectura por parte de Ficino del Comentario al Fedro de Hermias. Sin embargo, la epístola a Divicio recupera nuevamente lo establecido en el De divino furore y otra epístola, ésta dirigida a Naldo Naldi, revierte el orden del In Phaedrum. 
consecuentemente del De amore, donde se repite este orden), llama poderosamente la atención el que en todas las secuencias el furor poético venga asociado íntimamente tanto con el amatorio como con el religioso, al que Ficino asocia lo mistérico y el conocimiento profundo de la revelación divina. En el caso del Ión, ni en el propio comentario ni en el epítome que Ficino realizó y al que le puso el sobrenombre De furore poetico, la teoría clásica platónica se ve modificada; y en lo relativo al De amore, la intención casi terapéutica de su contenido para la salvación del alma hacía imposible que el hombre ascendiese en la jerarquía ontológica sin la armonización de sus partes discordantes, tarea a la que estaban abocadas tanto la poesía como la música nobles ${ }^{7}$. Esto parece revelar el hecho de que Ficino nunca consideró al furor poético como un elemento separado del verdadero propósito de su filosofía, la postulación de las relaciones entre las almas humanas y Dios, que implicaba su contención, en último término, en el espectro global del furor divino. Así, la poesía y, por tanto la creación artística, quedaban, en ese estado de posesión divina, puestas al servicio de la iluminación divina en el hombre, con lo que la individualidad del sujeto creador quedaba limitada al reflejo del poder divino a través de las más bellas creaciones; el paradigma estético quedaba reducido, de esta forma, a un papel mayoritariamente pasivo, el mismo que Ficino otorga a los poetas cuando los sitúa, en la Teología platónica, en un estadio más de las potencialidades de la razón en ascenso noético, junto con los filósofos, los sacerdotes y los profetas. Los cuatro tipos de furor serían, por tanto, la expresión de los cuatro tipos más excelsos de hombres dispuestos recíprocamente entre sí como expresión de la actividad de Dios en el alma humana, lo que hacía retornar a la clásica idea platónica del Ión, por la cual el hombre es incapaz, sin la ayuda de los dioses, de crear belleza verdadera alguna ${ }^{8}$.

El primer paradigma estético de los furores, basado en la pasividad del sujeto con respecto al lenguaje poético, de tal forma que fuese Dios quien «hablase a través de ellos como a través de trompetas ${ }^{9}$, si bien se insertaba en la tradición más directa y cercana a los pasajes explícitos del furor esbozados a lo largo del corpus platonicum, suponía, sin embargo, un peligro bastante pronunciado para la sostenibilidad global del sistema de Ficino, especialmente en cuanto atañía a la importancia de los procesos de iniaciación mistérica y purificación que él mismo había recogido de la tradición hermética a raíz de los encargos de traducción al respecto

$7 \quad$ Así mismo lo expresa ya en el De divino furore: «A ésta Platón la llama música y poesía nobles, la más poderosa imitadora de la armonía celeste, porque la más ligera (...) solo fascina por la suavidad de las voces» (Ficino, M., De Divino Furore, en: Sobre el Furor Divino y Otros Textos, Anthropos, 1993, Ed. de AzARA, P.). Esto corresponde a la clásica alegoría neoplatónica de la «doble poesía» y la «doble música». Cf. Nota 2.

8 Véase: Ficino, M., Teología platónica, L. XIII, Cap. II, Ed. de M. Allen y J. Hankins, Harvard University Press, Vol. IV, pp. 121-150. Aquí Hanegraaf se separa de Allen cuando afirma que el furor poético es, dentro de la perspectiva terapéutica del sistema ficiniano, capital para los estadios posteriores. Cf. HANEGRAAF, W., Op.cit., p. 562. En esto responde a los presupuestos de Ficino expuestos en el De vita coelitus comparanda, donde identificará al poeta con el sacerdote y en el que la poesía presentará un papel mucho más destacado en relación a la teoría de la melancolía inspirada. Véase: Brann, N., The Debate Over the Origin of Genius During the Italian Renaissance, Brill, 2002, p. 104.

9 Ficino, M., Op. cit., p. 127. Dirá igualmente de estos poetas inspirados que, una vez pasado el estado de furor, apenas entienden cuanto han proferido. 
que le había hecho Cosme de Médicis, anteponiéndolos incluso a la traducción de los propios diálogos de Platón ${ }^{10}$. Y la introducción del Corpus Hermeticum no solo representaba el enriquecimiento del neoplatonismo florentino, sino que así mismo suponía la asimilación de nuevos y radicales presupuestos en la relación entre el alma y las artes que, a colación de las innovaciones en el plano antropológico, iban a permitir la traslación de la teoría de los furores a un nuevo plano, y en concreto aquella que atañía particularmente al furor poético.

La naturaleza originaria de la separación gradual que la tradición neoplatónica clásica efectuó con respecto al lugar que Platón concedía a la poesía y a la creación inspirada por el furor poético (y muchas veces profético) fue también, en cierto modo, paradójica, pues, si bien permitía la revalorización del concepto de «sabio en las artes» (lo que posteriormente el Renacimiento transformaría en el concepto de "genio»), desviaba al furor poético de la en cierto modo autonomía que originariamente le concedía Platón en el Ión como estado propio de las Musas, contribuyendo así a integrarlo en el conjunto global de los furores divinos como un producto más del intelecto especulativo en los últimos estadios antes de la fusión con Dios. Sin embargo, esta misma paradoja da lugar a otra similar: y es que puesto que en el sistema de Plotino el furor no anula el conocimiento adquirido en estadios inferiores del alma, y se presenta como el ápice del proceso reflexivo, los efectos propios del furor poético como «aspecto» del furor divino serán profundamente estudiados precisamente a colación del clásico problema platónico de qué grado de autonomía podía concedérsele al artista, especialmente desde el plano epistemológico. Dicho de otro modo: ¿cuál es el valor epistemológico del furor poético entre los demás furores y en qué medida contribuye a la unión del alma con Dios dentro de la jerarquía ontológica?

Las innovaciones que el hermetismo y el valor propiamente neoplatónico de su sistema (que dependía en buena medida, como referíamos anteriormente, mucho más de los escritos de Plotino y demás pensadores como Proclo o Jámblico) hicieron que el tratamiento de Ficino de la cuestión del furor poético se fuese desviando cada vez a una subjetividad y una actividad más acentuada por parte del alma poseída, condiciones que reclamaba, como decíamos, la propia consistencia del neoplatonismo en cuanto a una corriente con amplio anclaje en la tradición ética del Helenismo y la mística orientalizante, y que tendía a la presentación de sabios o profetas casi divinos y dotados previamente de cualidades sobrenaturales con respecto a los otros mortales, lo que contradecía de entrada la afirmación de Platón de que el verdadero poeta debía estar en el fondo caracterizado por la ignorancia y la trivialidad que representaba con el fin de que no cupiese duda alguna en cuanto a la procedencia divina de sus versos. Esto resultó ya problemático para autores como Plutarco, que reconocían la imposibilidad de que los dioses revelasen sus mayores secretos a través de hombres vulgares y en todos los sentidos impuros, del tal forma que el concepto de posesión, y por tanto el de inspiración, no podía proceder totalmente de Dios:

10 Para una excelente introducción a la relación entre Ficino y el hermetismo, véase: Allen, M., «Marsilio Ficino, Hermes Trismegistus and the Corpus Hermeticum», en: Henry, J., y Hutton, S. (ed.): New Perspectives on Renaissance Thought, Duckworth, 1990, p. 39. Cf. también: Yates, F., Giordano Bruno and the Hermetic Tradition, Routledge and Kegan Paul, 1964, pp. 20-44. 
La voz no es la del Dios, ni la enunciación, ni la dicción, ni el metro, sino de la mujer [La Pitonisa]; Aquél dispone únicamente las visiones y crea una luz en su alma en relación al futuro; esto es, por tanto, el entusiasmo ${ }^{11}$.

Similares afirmaciones realiza Miguel Pselo (1018-1078) cuando afirma que en la actividad de la Pitonisa, al igual que en la de los que se dicen «entusiasmados», debe haber una actividad voluntaria que determine el mayor o menor rapto del alma por parte de Dios ${ }^{12}$. Y en mucha mayor medida con la llegada del cristianismo, el papel de la salvación no podía estar constreñido a un mero acto necesitarista, sino que tenía que contar con el papel de la voluntad pura predispuesta a recibir la Gracia; la propia inspiración mística cristiana necesita del don divino, pero ha de enraizarse en la preparación ascética del sujeto (uno de los grandes elementos que los Padres de la Iglesia tomaron del neoplatonismo).

Las relaciones entre el furor divino y el furor poético adquirieron, consecuentemente, un nuevo matiz en su directa inclusión dentro de la tendencia a enfatizar la importancia de la voluntad piadosa y santa en el proceso de conversión del hombre a Dios, que representaba un elemento clave en la platonización del cristianismo que siempre anheló Ficino a lo largo de toda su vida ${ }^{13}$. Así, su inicial concepción del furor derivada del mero comentario a los textos platónicos y que se presentaba como el producto de un alma poseída y casi inconsciente en cuanto a sus acciones y creaciones tenía que ser, necesariamente, revisada. Esto coincidía con el propio distanciamiento que Ficino establece en el De amore con respecto a Platón en cuanto al papel de la voluntad (uno de cuyos productos son los múltiples tipos de amor identificables con los niveles jerárquicos de los estratos del cosmos) en la determinación ontológica y vital del hombre; así, los tres tipos de vida que postula: voluptuosa, activa y contemplativa, no son totalmente propios del intelecto, sino que, antes bien, manan del afecto derivado de la cognición y permiten al hombre alcanzar en mayor o menor grado la esencia que le es propia ${ }^{14}$. La consecución de la vida contemplativa, al alcance únicamente de aquellos que ponen su alma al servicio de la luz verdadera y desdeñan todo

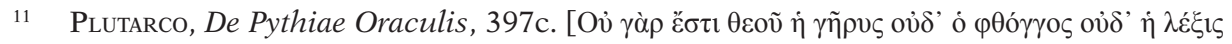

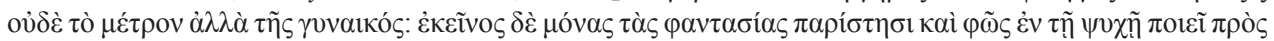

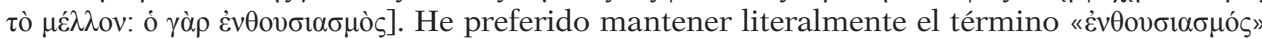
para mantener el sentido original griego y evitar equívocos. Cf. Ibídem, pp. 405ss., donde se cita un verso de la Estenebea, tragedia perdida de Eurípides, para afirmar que el arte poético no podía concederse a los «ö́povбot», esto es, al vulgo. En este sentido, era necesaria una propedéutica adecuada para poder llegar a estar «divinamente inspirado» y referir los misterios más profundos.

12 Psello, M., Acusación de Miguel Cerulario frente al Sínodo, en: Revue des Études Grecques, No 16, 1903, p. 391. (Ed de L. Bréhier). Como bien apunta P. Azara (Ficino, M., Sobre el Furor Divino y Otros Textos, Op.cit., p. XLIX de la Introducción), esto parece remitir a Jámblico (De Mysteriis Aegyptiorum, III, 2).

13 Cf. Allen, M., «Marsilio Ficino on Plato, the Neoplatonists and the Christian Doctrine of Trinity» en: Renaissance Quarterly, $\mathrm{N}^{\circ} 37$ (4), 1984, pp. 555-584. Producto de este anhelo de armonización fue, en todos los sentidos, la Teología platónica.

14 Ficino, M., De amore, Tecnos, 1986, (ed. de R. de la Villa), pp. 141-142. Esta separación de Platón ya se aprecia en el "Comentario a Plotino", IV, 4, 44, en: Opera Omnia, Basilea, 1576 (edición facsímil), p. 1749. [vita contemplativa libera est: activa ministra actionum atque fortunae: voluptuosa serva corporis] 
vestigio de sombra (de sensibilidad), esto es, que efectúan una catarsis, pueden en último término convertise en ángeles y, finalmente, unirse a Dios. Así, esto presupone que a la hora de recibir el furor, ya sea divino, poético o ambos, el alma recipiente deberá estar preparada para recibir su sacralidad, esto es, deberá estar libre de impurezas y consagrada a su grandeza; debe, en cierto modo, asemejarse a la excelencia del furor que la posee. Por tanto, la clásica teoría del Ión de que los dioses comunican su furor a través de hombres insanos o ignorantes es, por lo pronto, inasumible ${ }^{15}$. La comunicación de los misterios no solo ha de ser ejecutada a través de un alma de gran nobleza, sino que además ésta ha de participar piadosamente de la susodicha posesión, armonizándose, en este sentido, las dos alas del Fedro (245c-247a), las que suelen representar, en toda la tradición del neoplatonismo renacentista, al intelecto y a la voluntad. Así, los poetas que sean propensos a recibir el furor poético y a desplegar su creación deben, ante todo, estar previamente versados en el conocimiento de los misterios y presentar un alma suave, moralmente excelsa y tendente a la virtud y a la pureza. Ello explica el que, en los Commentaria al Fedro, Ficino invierta el orden de los furores del In Ionem, ya que, previamente a la creación y la proferencia de los versos inspirados, el alma debe estar poseída del furor profético y el furor religioso, a fin de que pueda predisponer su alma al conocimiento y a la fusión con lo sagrado. De ahí la afirmación de Michael Allen:

Mientras que para los griegos el furor simplemente denotaba una temporal, e incluso momentánea posesión que dejaba al médium atontado o parcialmente paralizado, la reconstrucción de Ficino en términos de «formada por Dios» o por las Formas Divinas, denota una inspiración más permanente y más constructiva: sustituye la transitoriedad de la antigua posesión por una experiencia más cercana a una conversión religiosa ${ }^{16}$.

La inspiración poética del sujeto divinizado debe, por tanto, venir mediada por una conversión que, a mi juicio, no implica necesariamente la presencia de «talento artístico» como convencionalmente se entiende, sino que remite más a una sabiduría de corte casi contemplativo y virtuoso, circunscrita únicamente a la voluntad santa que ha de querer ser poseída por Dios y, por tanto, que ha de disponer los medios adecuados a su alcance para ello, buscando en todo momento asimilarse

15 Es interesante recorrer, dentro del devenir dialógico del propio Platón, la evolución que va tomando internamente el concepto de la « $\mu \alpha v i ́ \alpha$ desde su primera postulación en el Ión hasta su más extenso tratamiento en el Fedro. De hecho, la tan radical autonomía que se presenta en aquél en cuanto al furor poético hace pensar que, una vez integrado en el conjunto del sistema platónico, su papel ontológico fuese inevitablemente variando, hasta llegar a representar un estadio asociado al amor y la contemplación. De ahí que, en su análisis del Fedro (y especialmente en los Commentaria et argumenta de 1490) a Ficino le resultase más

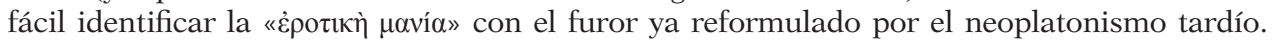
Esta identificación, que fue también llevada a cabo por Proclo, es, a juicio de autores como Sheppard, excesiva. Véase: SHePPARd, A. Studies on the Fifth and Sixth Essays on Proclus' Commentary on the Republic, Vandenhoeck und Ruprecht, 1980, p. 181. Sin embargo, otros como Dodds o Verdenius optan por aislar cualitativamente este furor amoroso que refiere Platón en el Fedro de los otros furores. Véase para esta tesis: Verdenius, J., "Der Begriff der Mania in Platons Phaidros» en: Archiv für Geschichte der Philosophie, No 44, 1962, pp. 132-150.

16 Allen, M., The Platonism of Marsilio Ficino. A Study of His Phaedrus Commentary, Its Sources and Genesis, University of California Press, 1984, p. 58. 
a la excelencia de ese furor. Y esto viene precisamente por el hecho de que, pese a irse distanciando poco a poco con respecto al furor estrictamente platónico, Ficino nunca dejase de concebir a la poesía, ya fuese «enfurecida» o no, como una parte fundamental del sistema filosófico, pero que, como tal, no dejaba de estar puesta al servicio de intereses que escapaban en último término a su emancipación absoluta. Su función ulterior era, por tanto, servir de método para despertar a las almas de su prisión corpórea y como un signo terrestre de la inmortalidad del alma. Es, por tanto, ancilla philosophiae, y de ahí que en Ficino no podamos todavía hablar de "poética», sino de "poesía» ${ }^{17}$.

La inexistencia de una contraposición real en Ficino entre poética y poesía va a delimitar claramente la misma inexistencia de un "genio poético» tomado como base del valor individual y subjetivo de la propia creación artística que, como vemos, solo se toma como el producto del alma pura, uno de cuyos efectos son esos mismos versos divinos que se profieren en estado de posesión. De hecho, en los propios Commentaria et argumenta al Fedro, donde el furor ya encuentra una clara, aunque pequeña en proporción, presencia del sujeto, Ficino empleará, para referirse al proceso de instrucción que el alma ha de realizar voluntariamente para acompañar al furor, el verbo "formare», que en este contexto no parece que se separe mucho del significado común de «preparar», «labrar» o «disponer». El furor poético, por el contrario, sí instruye en cuanto procede directamente de Dios (no de las Musas, como en Platón), que es en todo momento objeto de conocimiento intuitivo y contemplativo:

Conviene, para conseguir el furor poético con que los hombres de costumbres divinas son instruidos y los misterios divinos son cantados, que el ánimo del futuro poeta esté tan sensibilizado que casi sea tierno y suave. Sobre todo que sea puro. El dominio del poeta es muy amplio y de materia muy variada. El ánimo, pues, formado por sí mismo muy fácilmente, debe someterse a Dios formador. Lo cual, ciertamente, se expresa a través de la suave ternura. Pero, si por una facilidad de este tipo hubiese adoptado ya conductas ajenas o maleadas, no se podría instruir entretanto mediante conductas divinas; por lo cual es añadido por Sócrates que debe ser totalmente puro —es decir, inmaculado—y libre ${ }^{18}$.

17 Soranzo, M., Poetry and Identity in Quattrocento Naples, Routledge, Taylor-Francis, 2016, p. 99. Cf. también: Greenfield, C., Humanist and Scholastic Poetics (1250-1500), p. 236. En este punto destaca la tesis de A. Chastel, que afirma que, contrariamente a lo que se piensa, la poesía en Ficino sí presenta un fin en sí mismo, y no se expresa únicamente como un elemento residual del furor divino. Sin embargo, el escaso tratamiento por parte de Ficino de las artes en sí hace pensar que si exaltaba de tal modo la poesía era porque, combinada con las armonías musicales más nobles, hacía elevarse al alma a las regiones supracelestes. Así mismo, como bien apunta D. P. Walker, lafigura del poeta-músico como cantor de los misterios se remonta a tiempos casi inmemoriales. Véase: Chastel, A., Marsile Ficin et l'Art, Droz, 1954, p. 132. Cf. WALKER, D.P., Music, Spirit and Language in the Renaissance, Variorum, 1985. (ed. de P. Gouk).

18 Ficino, M., In Phaedrum Commentaria et Argumenta, Cap. IV, en: Sobre el Furor Divino y Otros Textos, Anthropos, 1993, pp. 66-67. 
Por tanto, el paradigma fundamental del furor poético se expresa en los términos de una «locura divina» que, por contraposición a la insanía, se presenta en los sabios purificados previamente a través de los misterios ${ }^{19}$.

Hemos visto, por tanto, que la evolución del concepto de furor poético en la obra de Ficino acompasa claramente la propia evolución del concepto de furor divino, del que parece inseparable como elemento de posesión de un alma pura y santa dispuesta a imitar la grandeza y excelencia de Dios con versos extasiados de contenido místico y profético. Sin embargo, la renovación del neoplatonismo con respecto a la « $\mu \alpha v i ́ \alpha »$ platónica y la presencia del cristianismo fueron dos factores decisivos para que la psicología del artista comenzase a entreverse progresivamente y así la subjetividad de la creación estética no quedase únicamente en un residuo puesto al servicio de la suma objetividad divina. Sin embargo, pese a las afirmaciones del In Phaedrum de que, en el fondo, todos los otros furores pueden desplegarse en último término como furor poético y el hecho de que la voluntad piadosa anhelase la posesión poética y pusiese los medios adecuados para la creación, no existe aún, a mi juicio, la libertad necesaria para afirmar que la psicología artística halla en Ficino un despliegue explícito, al menos desde la lectura directa de los textos ${ }^{20}$. Sí se puede, no obstante, inferir la presencia de una cierta subjetividad que, de la mano de la voluntad, servirá para introducir el campo del «genio poético» y la exaltación inspirada que, no debemos olvidar, seguirán puestas al servicio de la contemplación y unión con Dios, pero ahora bajo una perspectiva radicalmente nueva. Dos textos de Cassirer y Saitta ilustran, respectivamente, esto mismo:

Pero a este proceso que tiende a elaborar las bases teoréticas y las condiciones del concepto de subjetividad se le opone otro en que se destacan claramente las fuerzas que a la postre determinan e informan todo el movimiento espiritual de la época. El fundamento sobre el que Ficino asienta su doctrina del alma y su doctrina de la inmortalidad no es tanto su concepción general del conocimiento como su concepción de la voluntad humana. La doctrina del Eros constituye la verdadera piedra angular de la psicología de Ficino. Es en realidad el centro de todos los esfuerzos filosóficos de la Academia de Florencia ${ }^{21}$.

La filosofia del Ficino movendo da una concezione religiosa della vita s'orienta verso una visione soggettivistica, in cui però la religione constituisca sempre il punto d'arrivo. Ansi il suo soggettivismo mal s'intenderebbe se non fosse sospeso all'idea centrale che penetra tutte le pieghe del suo pensiero; l'idea di Dio ${ }^{22}$.

Este será, justamente, el punto de partida desde el que Giordano Bruno realizará, en De gli eroici furori (1585), su revisión de los paradigmas del furor poético ficiniano e introducirá una nueva estructura radical a la hora de definir el estadio

19 De ahí la referencia en el De amore a la alienación que expresa el furor divino como opuesta a la enfermedad vulgar generada por el exceso de bilis negra. (De amore, VII, 3). Esto mismo ya se había tratado al comienzo del De furore poetico, que comprendía el epítome al «In Ionem». La unión entre poesía y profecía tiene claras reminiscencias del Pimandro (I, 22).

20 Cf. Allen, M., Marsilio Ficino and the Phaedran Charioteer, University of California Press, 1981, pp. 84-85.

21 CASsirer, E., «El problema del sujeto y el objeto en la filosofía del Renacimiento», en: Individuo y cosmos en la filosofía del Renacimiento, Emecé Editores, Buenos Aires 1951, p. 168.

22 Saitta, G., Marsilio Ficino e la Filosofia dell'Umanesimo, Fiammenghi-Nanni, 1954, p. 239 . 
de la creación poética (y en general, artística) en el seno de un sistema filosófico plenamente embebido del Manierismo.

2. La relectura de Bruno en el Gli eroici furori (1585): los furores, al SERVicio de LA POÉTICA INFINITA DEL GENIO

Con la excepción de los clásicos y ya lejanos artículos de Giancarlo Maiorino y Giorgio Barberi Squarotti ${ }^{23}$, apenas existen trabajos recientes consagrados íntegramente al estudio de la relevancia filosófica que la poética (y con ella el furor poético) ha conllevado en el seno del pensamiento de Giordano Bruno (1548-1600)24. Uno de los motivos principales quizás remita a la nueva dispersión que el propio elemento del furor experimentó desde la muerte de Ficino en 1499 hasta la publicación de Gli eroici furori en 1585. En efecto, el transcurso de casi un siglo sirve para testimoniar cómo la entrada del Manierismo volvió paradójicamente a limitar el campo de acción del furor hasta terminar cometiendo un parricidio contra su autonomía, y esto precisamente de la mano de la génesis definitiva del concepto moderno de subjetividad, y con ella de la primera sistematización de una poética en sentido estricto, centrada en la aplicación práctica de la inspiración (el remanente estético del furor) en la creación individual, algo que nunca había interesado a la Academia de Ficino y cuyo concepto de voluntad, si bien, como hemos visto, remitía a la purificación y al querer ser poseído, no llegaba a alcanzar ${ }^{25}$.

En torno a las primeras décadas del S. XVI, las teorías estéticas neoplatónicas asociadas a la inspiración comenzaron a fusionarse con ciertos preceptos de orden práctico derivados de la Poética de Aristóteles, que experimentó una creciente relectura y estudio a lo largo de estos años ${ }^{26}$. De hecho, el nacimiento de la psicología artística y la necesidad de establecer adecuadamente las fronteras del arte debe mucho a la proliferación del gusto individual y la tendencia a determinar precisamente cómo esa posesión alcanzaba, en el acto de creación, un amplio desarrollo ya no desde el ámbito divino, sino más bien desde el ámbito humano ${ }^{27}$. Es difícil

23 Maiorino, G., «The Breaking of the Circle: Giordano Bruno and the Poetics of Immeasurable Abundance» en: Journal of the History of Ideas, Vol. 38, $\mathrm{N}^{\circ}$ 2, 1977, pp. 317-327. BARBeri Souarotti, G., "Per una Descrizione e Interpretazione della Poetica di Giordano Bruno» en: Studi Secenteschi, Vol. I, 1960, pp. 39-52.

24 La excepción la constituye el artículo elaborado por A. Siani en 2007: «La Poetica degli Eroici Furori», en: Catanorchi, O., y Pirillo, D. (ed.): Favole, Metafore, Storie. Seminario su Giordano Bruno, Edizione della Normale (Pisa), pp. 577-599.

${ }_{25}$ Cf. Ficino, M., Sobre el Furor Divino, Op.cit., p. LXVIII (Estudio Introductorio).

26 Para una excelente síntesis del impacto de la Poética aristotélica en la Italia del S. XVI, véase: JAVITCH, D., "The Assimilation of Aristotle's Poetics in Sixteenth Century Italy», en: Kennedy, G. et al.: The Cambridge History of Literary Criticism, Vol. III, pp. 53-66. (ed. de G. Norton).

27 De hecho, ya en los Poeticorum libri tres de 1527, Marco Girolamo Vida entrevía que el furor poético debía estudiarse en clave práctica desde sus efectos en la creación individual, y no desde consideraciones metafísicas en torno a su origen y procedencia. (Poeticorum Libri Tres, I, vv. 75-79). 
trazar, del mismo modo, la evolución conceptual de toda esta terminología estética desde la primera correspondencia entre la « $\mu \alpha v i ́ \alpha »$ y el furor hasta el empleo definitivo del término «inspiración», pasando por conceptos como «entusiasmo»o «genio» que, como vimos, carecían de precisión dentro de la propia complejidad metafísica que suponía determinar no solo la naturaleza del furor poético, sino su relación con respecto al furor divino como tal. De hecho, la tensa evolución que se produjo contemporáneamente entre la objetividad y la subjetividad en el plano estético introdujo igualmente un cierto número de elementos auxiliares para intentar armonizar ambos polos (especialmente en cuanto esto concernía la armonización, en último término, de las relaciones de poder entre Dios y el hombre); elementos como la melancolía, las visiones o los sueños proféticos sirvieron de receptáculo para la probación de la fuerza de uno u otro, así como de la distancia ontológica entre los mismos ${ }^{28}$. Lo cierto es que, de uno u otro modo, la entrada de Aristóteles en materia estética propició que el debate en torno al furor y la creación artística se acuciase enormemente.

Es importante tener en cuenta que la difícil e incipiente relación entre la teoría poética (como conjunto de reglas aplicadas a la creación) y la poesía (relacionada más directamente con la divinidad) tampoco se estipula límpidamente a lo largo de la obra de Bruno; aun así, mientras que la poesía y todo cuanto concierne a los furores se dispersa a lo largo de la diversidad de su sistema, sus pareceres en torno a la poética como tal sí hallan eco explícito en los primeros diálogos entre Tansillo y Cicada al comienzo de los Heroicos furores, donde, como preámbulo y excurso a la justificación de la relación entre las Musas y el Furioso, se desarrolla todo un ataque directo y mordaz contra la teoría de la imitación aristotélica y el cumplimiento de las reglas para la «buena poesía». Y no es a mi juicio casual el que esta breve disquisición (que pronto analizaremos) se sitúe precisamente al comienzo de la obra, como antesala de la exposición de las características y naturaleza del sujeto heroico, precisamente como señal de que la relación paradigmática fundamental que delimitará la unión del alma con Dios en términos estéticos ha de remitir siempre al despliegue individual de un alma creadora que «cede» parte de su potencial creador a la conquista de un infinito que, por el hecho de serlo, le acrecienta y atormenta al mismo tiempo. Esta infinitud no debe hacernos creer que estamos nuevamente ante un concepto dotado de fuerza inconmensurable para anular las dimensiones humanas, sino que, antes bien, acontece para dotarlas de completitud y perfección. Tampoco debemos olvidar que en los Furores, el último de los llamados «Diálogos Italianos», Bruno ya ha roto con la jerarquía ontológica y antropológica postulada por el neoplatonismo de Ficino y que él mismo había asumido parcialmente en el De umbris idearum (1582); consecuentemente, las facultades sensibles y las facultades nóeticas estarán puestas en nuevos planos, y con ellas la acción del furor.

28 En el caso de la melancolía inspirada, ésta se convirtió en un elemento decisivo a la hora de establecer las diferencias entre la posesión inspirada y el genio creador que distancian los paradigmas de Ficino y Bruno. Cf. para una aproximación a la cuestión: KLIBANSKY, R., Panofsky, E., y SaXl, F., Saturn and Melancholy: Studies in the History of Natural Philosophy, Religion and Art, Nelson, 1964. Véase también: L. Catana, L., The Concept of Contraction in Giordano Bruno's Philosophy, Ashgate, 2005, pp. 66-68. 
Las mismas dificultades que arrastró Ficino a la hora de catalogar su concepción del furor poético acompañaron la peculiar recepción que de éste hizo Bruno, especialmente dando muestras de una aparente y cierta indiferencia por su independencia con respecto a la otra posesión común y general que respondía al furor divino. De hecho, las pocas veces en las que Bruno formula una cierta clasificación de los furores, lo hace en términos muy generales y apelando a la clásica distinción ficiniana del De furore poetico, donde hallamos aquella enajenación provocada por la insanía puramente humana (la enfermedad mental) y la enajenación provocada por la divinidad, por la que el alma se ilumina y es conducida a lo superior ${ }^{29}$. Así mismo lo expresa en boca de Tansillo al comienzo del tercer diálogo de los Furores:

Se suponen, y de hecho existen, varias especies de furores, todas las cuales se reducen a dos géneros: los unos manifiestan únicamente ceguera, estupidez e ímpetu irracional, tendiendo a la insensatez ferina; consisten los otros en cierta divina abstracción por la cual algunos alcanzan a ser en verdad mejores que los hombres ordinarios ${ }^{30}$.

Sobre la base de esta dicotomía, el influjo de la divinidad va a seguir manteniendo una autoridad indiscutible, pero, como veremos, lo hará bajo unas condiciones radicalmente novedosas. La apelación a la «abstracción», que en terminología bruniana remite al ascenso noético desde la multiplicidad a la unidad (por contraposición a la "contracción», que efectúa el despliegue a la inversa) permite inferir que la presencia del furor, una vez rota la jerarquía neoplatónica, va a tener que apelar no solamente a las regiones inteligibles del alma, sino igualmente a sus partes inferiores y que más directamente interfieren con la sensibilidad, de ahí que Bruno introduzca el elemento del «corazón» como un intermediario entre la dinámica que mueve el afecto y la pura cognición. Esto va a corresponderse con la verdadera significación que va a constituir calificar al furor de heroico, que implica una posesión inmanente, plenamente imbricada en la naturaleza como reflejo, y no estadio propio inferior, por parte de lo $U_{n o}{ }^{31}$. Y así, ello conlleva una radical distinción en la naturaleza propia del furor bruniano con respecto al paradigma ficiniano, y es que la purificación ya no será una condición extrínseca necesaria para la santidad del alma poseída, sino que adquirirá una dimensión mucho más profunda en esta inmanencia que acerca propiamente a posturas panteístas, también de la mano de la revitalización que la sensibilidad experimentó a lo largo de toda la obra

29 Ficino, M., De Furore Poetico, en: Sobre el Furor Divino y Otros Textos, Op.cit, p. 31. La misma contraposición se establece, con algunas variantes, en el De amore (VII, 3).

30 Bruno, G., Los Heroicos Furores, Tecnos, 1987, p. 56. (ed. de M. González Prada).

31 Consecuentemente, la ruptura parcial de la metafísica neoplatónica va a representar igualmente la ruptura de la moral ascética y la creación de todo un nuevo espacio propio de dominio humano, el de la magia natural, que va a simbolizar la obtención progresiva de poderes por parte del alma en armonía con la estructura del cosmos. Justamente, la inmanencia y la reivindicación de la funcionalidad propia de cada región anímica erradica toda posibilidad de subyugación de una facultad sobre otra, pues esto último haría volver nuevamente al sistema clásico de Ficino. Cf. Gatell, R., "De la Reforma Moral en los Diálogos Italianos de Giordano Bruno. La Apología del Esfuerzo y el Elogio de las Manos» en: Epos: Revista de Filología, Vol. 23, 2007, pp. 183-196. 
bruniana; esto es, la catarsis del alma no va a ser ya del todo ajena a su propio proceso de elevación ${ }^{32}$.

Sin embargo, esto no quiere decir que el tipo de furor adoptado por Ficino fuese del todo ajeno a la conceptualización del héroe, ni tampoco que la esencia del neoplatonismo quedase totalmente superada. El furor bruniano debe mucho al furor ficiniano. Todo se concentra en, como afirma Pietro Omodeo, una diferencia terminológica que representa, en efecto, un giro filosófico decisivo:

While Ficino regards the desire for divine beauty and goodness as a form of ascesis - a mystical drive to experience and annihilate oneself in God's infinityBruno extols the "divine subject's» heroism and his realization of great wordly achievements, in accordance with the civil values of the Spaccio. The cosmological dimension of Bruno's discourse, in the Italian dialogues, permits to conceive of this desire for infinity as inmanent within nature. It seems therefore that Bruno can dismiss Ficino's distinction of a twofold ethics, divided into a worldly realm of application and a theological one, since he deems infinity to be a characteristic of nature itself, and not exclusive to $\operatorname{God}^{33}$.

Esto tampoco presupone que Ficino desestimase la infinitud de Dios tal y como se expresa en la naturaleza, pero su amplia observancia de la voluntad piadosa y santa del cristianismo y la acción de la triple vida (ferina, activa y contemplativa) en la determinación de la esencialidad humana complicaban sobremanera la introducción de una inmanencia que podía resultar peligrosa, en cuanto a que conllevase una exaltación y reivindicación indebida de lo sensible o lo material. Y contrariamente a lo que se cree, Bruno siempre mantuvo el elemento de distanciamiento con lo que consideraba la «moral vulgar» en relación a la "moral heroica», enfatizando siempre la separación de la vida voluptuosa (tendente a los estratos bajos de la materia) de la vida contemplativa y santa (tendente a la adquisición de la belleza y la bondad infinitas). La única diferencia reside en el hecho de que, ante la ruptura de la jerarquía neoplatónica, la actitud ascética será extraída del sistema filosófico y reemplazada por un elemento de tensión dialéctica entre la finitud y la infinitud motivada por aquella misma ruptura, y es aquí donde se situará propiamente el furor poético como expresión elevada de la misma ${ }^{34}$.

La infinita desproporción que establece la cosmología y la ética brunianas entre el intelecto deseoso de la contemplación y el goce de la infinitud de Dios y las verdaderas fuerzas alcanzables al sujeto finito determina que en la posesión heroica del

32 Esto se corresponde igualmente con la filosofía natural y cosmológica que acompasó toda la obra de Bruno y que se acerca a la máxima abstracción inmanente de lo diverso en la unidad monádica. Cf. Védrine, H., La Conception de la Nature chez Giordano Bruno, Vrin, 2000 .

33 Омодео, P., Copernicus in the Cultural Debates of the Renaissance: Reception, Legacy, Transformation, Brill, 2014, p. 344.

${ }_{34}$ No obstante, existe pese a esto una larga continuación de la tradición neoplatónica entre Ficino y Bruno en cuanto a la caracterización básica del objeto de la infinita belleza y el infinito amor que es Dios-Uno, así como a la recepción de toda la tradición de la mística amorosa. Véase: HanegraAF, W., «Under the Mantle of Love: The Mystical Eroticisms of Marsilio Ficino and Giordano Bruno», en: Hidden Intercourse: Eros and Sexuality in the History of Western Esotericism, Fordham University Press, 2011 (ed. de HanegraAF, W., y Kripal, J.), pp. 175-208. 
furioso el furor no se halle nunca en reposo, sino que se adecúe a la agitación que el propio sujeto experimenta ante el desborde del objeto que anhela amorosamente con amor igualmente infinito, pero constreñido a facultades finitas. Y puesto que entre aquellos (Dios y el sujeto) existe una distancia infinita, el amor con que dicho furor debe estar acompañado debe ser, en cierto modo, inmoderado, de ahí que en su más alto grado no entienda ni de virtud ni de vicio. De ahí que el furor divino esté, como participante del sujeto heroico, arrebatado por los contrarios, por el anhelo de unidad en la multiplicidad y, en definitiva, por la excelente locura. Y es que esta inmoderación, que Ficino jamás hubiera podido aceptar, no es un mal o un vicio, sino la consecuencia metafísica necesaria ante el deseo infinito de infinitud de un ser finito en la finitud ${ }^{35}$. De ahí que, coincidiendo con Ficino en cuanto a la afirmación de que el furor es una iluminación hiper-racional, Bruno estipule en los Furores que al igual que existe una locura por defecto (que tiende a la enfermedad humana), existe también una locura propia de aquellos que están dotados de más entendimiento ${ }^{36}$.

Con la postulación del furor heroico, Bruno daba a entender de forma latente que la estética ficiniana del pre-subjetivismo de la voluntad santa y purificada había de ser reemplazada por una posesión desmedida que contribuyese a mantener esa tensión amorosa desproporcionada entre Dios y el alma, y no a amainarla, precisamente porque el propio Furioso ni quiere tranquilizar su agitado intelecto si con este sufrimiento ha de mantener su amor y deseo infinitos (Bruno llega a calificar al amor heroico de «tormento ${ }^{37}$ ) ni tampoco ha de reconducir todos sus pensamientos hacia el intelecto, sino que ha de armonizarlos con las facultades que les son propias. La inmanencia en la naturaleza y la uniformización ontológica bruniana conlleva igualmente la ruptura de la jerarquización activa de las facultades y su disposición, en último término, en casi el mismo plano ${ }^{38}$. Esto influirá directamente, por tanto, en la recepción que el sujeto va a realizar de dicho furor, y en las propiedades que caracterizarán al furor poético y a la poética en sí tal y como Bruno los presenta en contraposición a Ficino y a Aristóteles, respectivamente. Partiendo de la disyuntiva antedicha en torno a los tipos de locura, en la continuación del discurso de Tansillo se vuelve a establecer una contraposición, esta vez entre los diferentes tipos de individuos que reciben esta locura divina de acuerdo con el modo en que lo hacen, distinguiendo entre aquellos que únicamente participan de ella como receptáculos e instrumentos de su acción, y aquellos que, por el contrario, recibiéndola con elevado

35 Véase: Ebbersmeyer, S., «The Philosopher as a Lover: Renaissance Debates on Platonic Eros» en: VV.AA: Emotion and Cognitive Life in Medieval and Early Modern Philosophy, Oxford University Press, 2012, (ed. de M. Pickavé, M., y Shapiro, L.), p. 150, (pp. 133-156).

36 Bruno, G., Los Heroicos Furores, Op.cit, pp. 81-82.

37 Ibídem: p. 47.

38 Esto no significa que el intelecto y la sensibilidad gocen de la misma excelencia en el sujeto, sino que sus funciones son, en tanto que así dispuestas por la naturaleza, igualmente buenas como partes integrantes del Todo. Consecuentemente, anular la sensibilidad a través de la purificación es eliminar uno de los ejes de la contracción divina en lo finito. Por eso en los Furores Bruno apela, en boca de Tansillo, a evitar la rebelión de los pensamientos en pro del intelecto, y a reconducirlos a la armonización de la sensibilidad y la inteligibilidad. Cf. Ibídem, pp. 86-87. 
entendimiento y lúcido espíritu, se convierten en verdaderos sujetos activos, esto es, en los principales artífices y causas eficientes de las cosas:

Y éstos [los furores divinos] son a su vez de dos especies, pues ciertos individuos, al haberse convertido en habitáculo de dioses o espíritus divinos, dicen y obran cosas admirables de las que ni ellos mismos ni otros entienden la razón; son éstos generalmente elevados a tal situación desde un primer estado de incultura e ignorancia, introduciéndose el sentido y espíritu divino en ellos como en un receptáculo purgado, vacíos como se hallan de espíritu y sentido propios. (...) Otros, por estar avezados o ser más capaces para la contemplación y por estar naturalmente dotados de un espíritu lúcido e intelectivo, (...) agudizan los sentidos por medio del fuego del deseo y el hálito de la intención y, con el aliento de la cogitativa facultad, encienden la luz racional, con la cual ven más allá de lo ordinario; y éstos no vienen al fin a hablar y obrar como receptáculos e instrumentos, sino como principales artífices y eficientes ${ }^{39}$.

Esta distinción encaja perfectamente no solo en cuanto a las tesis antiascéticas e inmanentistas que se desarrollan a lo largo de los Furores, sino igualmente en cuanto a la reivindicación de la magia como elemento de poder causal en el hombre poseído dentro del ámbito de la filosofía natural, tesis que también se trasladan al De magia (circa 1590) y al De vinculis in genere (1591). Si la magia representa la expresión del hombre «eficaz» en el ámbito de la naturaleza, la poesía, y más propiamente la poética como tal, va a ser el símbolo de este poder en el ámbito de la moral. Y un nuevo giro con respecto a Ficino se dará del lado de que el hombre no ha de dejarse arrastrar por lo divino en ningún sentido, sino que debe, al contrario, reafirmar la excelencia de su propia humanidad de suerte que, paradójicamente, nunca haya de dejarse unir a Dios directamente. Aquellos a los que llena la divinidad aniquilando su actividad podrán ser más potentes en sí (son pura actividad divina) pero no más dignos ni eficaces, pues en en aquellos que afirman, aun trágicamente, su "Yo», es donde se observa la verdadera relación heroica del alma del Furioso con respecto a Dios, su anhelo por estar en continuo proceso de divinización ${ }^{40}$. Esto conduce a la idea de que los ritos religiosos, y más generalmente, todo conjunto de prácticas regladas, es absolutamente incompatible con el verdadero furor de naturaleza heroica; es, en propias palabras de Bruno, «la magia de los desesperados» ${ }^{41}$.

Aplicado al dominio de la poesía y la poética, el conjunto de prácticas regladas que Bruno condenará enfáticamente serán las efectuadas por Aristóteles, que, de acuerdo con lo antedicho, representan el canon para aquellos incapaces de

39 Bruno, G., Los Heroicos Furores, Op.cit, pp. 56-57. Esta misma distinción se hallará posteriormente en el Idiota triumphans (1586). Cf. Ingegno, A., Cosmologia e Filosofia nel Pensiero di Giordano Bruno, La Nuova Italia, 1978, pp. 192-193.

40 De hecho, Bruno dirá de los hombres que son meros receptáculos de la divinidad que son como «asnos que llevan sobre sí los sacramentos» (Los Heroicos Furores, Op.cit, p. 57). Cf. Ordine, N., Giordano Bruno and the Philosophy of the Ass, Yale University Press, 1996. Una crítica similar se halla en la Cábala del caballo Pegaso (1585), publicada el mismo año que los Furores, donde llegará a afirmar que estos hombres interfieren en el proceso de contemplación bajo el aparente velo de la religión. (Oeuvres Complètes, Les Belles Lettres, 2000, Vol. VI, pp. 23-25).

41 Bruno, G., De magia naturali, II. 17-24. 
desplegar su propia actividad de forma excelente y eminente. La creación poética, que hasta el momento había estado completamente supeditada a la posesión divina tal y como la había conceptualizado Ficino, evolucionará hasta dar lugar al «genio poético», aquella cualidad del Furioso que desdeña toda regla por ser él mismo excelso creador y «eficiente» de los versos que profiere, siendo éstos así mismo en último término divinos. ¿Y dónde queda el furor poético propiamente dicho? Podemos decir que, al concentrar la actividad poética en el sujeto, aquello a lo que convencionalmente llamaríamos furor poético, quedaría ahora redefinido como la posibilidad inmanente que el rapto divino ofrece al furioso para crear versos geniales que, elevando la individualidad del poeta, a su vez lo integran en el reflejo armónico del Todo; este rapto, por tanto, se equilibra tanto de uno como de otro lado, y en su difícil conciliación, representa el espíritu fundamental de la obra bruniana: la superación de la lucha de los contrarios, especialmente cuando tenemos en cuenta la infinita desproporción que se da entre el sujeto finito y el deseo infinito de infinitud. La creación poética está en todo momento, por tanto, revestida de divinidad ${ }^{42}$.

Esta nueva concepción no solamente revisaba y superaba el paradigma ficiniano, sino que, más aún, representaba, como veníamos afirmando, un claro y directo ataque contra la Poética de Aristóteles, no específicamente contra la consistencia de las reglas para la creación artística que en ellas se contiene, sino principalmente por la tesis principal que la circunscribe, esta es, que los géneros literarios han de estar precisa y delimitadamente señalados y separados, de tal forma que puedan erigirse fronteras entre ellos, con el fin de tratar de discernir la "verdadera poesía» de la "falsa poesía» ${ }^{43}$. La estricta delimitación aristotélica del espacio adscrito al arte no viene precisamente de un relativismo del género, sino, antes bien, de la

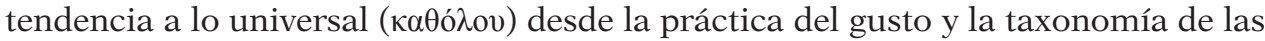
facultades involucradas en el proceso de creación. El propio Aristóteles afirmaba en la Retórica que fenómenos poéticos como la metáfora requerían de una aguda mente filosófica para captar su verdadero significado ${ }^{44}$; sin embargo, el problema venía en la ejecución de la práctica poética y en el sujeto creador que aquel presentaba, constreñido en el ejercicio casi lógico de sus facultades e imposibilitado para la salvación del alma, que ya desde Ficino constituía el elemento decisivo tanto de la poesía como del furor poético. Así, la liberación de las reglas aristotélicas permite la multiplicación de los tipos de poesía casi hasta el infinito, tantos como sujetos enfurecidos haya a la predisposición poética. El único valor de las reglas (si se puede usar este término) es su caracterización a posteriori, esto es, como símbolo del potencial y despliegue facultativo de cada uno de los furiosos, y no como axiomas prescriptivos que anulen la libertad de invención. Así mismo lo expresa Tansillo:

Concluyes bien, pues la poesía no nace de las reglas, salvo en algún caso accidental, sino que las reglas derivan de la poesía y, por ello, tantos son los géneros y especies de verdaderas reglas cuantos son los géneros y especies de verdaderos

42 Véase: Ghosh, R., Transcultural Poetics and the Concept of the Poet: From Phillip Sidney to T. S. Eliot, Routledge, 2017, p. 35.

43 Ordine, N., Giordano Bruno and the Philosophy of the Ass, Yale University Press, 1996, p. 160.

44 Aristóteles, Retórica, 1405a-1412a. Cf. M. Lazarus: Aristotle's Poetics in Renaissance England, (Tesis Doctoral), Oxford University, 2013. 
poetas». (...) Y digo que existen y pueden existir tantas clases de poetas cuantas maneras de sentimientos e invenciones humanas puedan existir ${ }^{45}$.

Y desestimando a los seguidores de la poética aristotélica siguen de este modo:

Tansillo: Ten por cierto, hermano mío, que éstos [los seguidores de las reglas de Aristóteles] son verdaderas bestias, pues no consideran que esas reglas deben servir principalmente como manifestación de la poesía homérica (u otra semejante) en particular y que están ahí para mostrar de vez en cuando un poeta heroico cual fuera Homero, y no para formar a otros que - con diferentes inspiraciones, artes y furores- podrían ser iguales, semejantes y hasta más grandes en géneros diferentes. Cicada: De manera que Homero en su género no fue poeta que dependiese de reglas, sino que, por el contrario, él es origen de esas reglas que sirven a quienes son más aptos para imitar que para inventar $(\ldots)^{46}$.

Precisamente, por el hecho de que cada uno de los furiosos expresa su individualidad creadora de una forma radicalmente distinta, pero todos ellos participan del furor que les suscita el amor infinito de Dios, la experiencia poética en Bruno es, como afirma Alberto Siani, "una radical experiencia de verdad», y así mismo, el verdadero poeta será, en el fondo, el filósofo heroico, que eleva su intelecto y sus facultades superiores a través de los versos proferidos divinamente desde el corazón (de ahí que Bruno apele a la «cima del Parnaso», esto es, la cima del corazón). Y por tanto, frente a la imitación aristotélica, la invención y fascinación del furioso le lleva a desplegar su creación en el modo poético por excelencia, la "poesía filosófica», aquella misma que constituye el despliegue dialógico de los Furores ${ }^{47}$. Este principio de diversidad vital que permea toda la obra bruniana viene muy a colación de la profunda crítica al petrarquismo que Bruno recoge en el prefacio dedicatorio a Phillip Sidney, afirmando que el tópico de amor estilizado y cortesano que profesan los poetas seguidores de Petrarca no es más que la expresión de un lenguaje estéril incapaz de salir de su propio círculo de formalismos y repeticiones, aniquilando el potencial creador del furioso, que acaba siendo nuevamente constreñido por paradigmas análogos a los aristotélicos. Este antipetrarquismo, por tanto, enlaza con una teoría de la creación poética que ya presenta, siguiendo el antiguo concepto platónico de la emoción, el prototipo del genio poético que, desligado de pedanterías formales y estilismos vacuos, se aferra a su propia experiencia del infinito para producir los más diversos versos ${ }^{48}$.

45 Bruno, G., Los Heroicos Furores, Op.cit, pp. 32-33. Curiosamente, Bruno cita aquí como criterio de discernimiento de los verdaderos poetas el «utile dulcis» de Horacio (Arte Poetica, 333-334). Maiorino apunta aquí a la posible crítica latente con respecto a la exaltación del «utile» sobre el «dulcis» motivado por la Contrarreforma y por la obra de Lodovico Castelvetro (1505-1571). Véase: G. Maiorino, G., «The Breaking of the Circle: Giordano Bruno and the Poetics of Immeasurable Abundance» en: Journal of the History of Ideas, Vol. 38, $\mathrm{N}^{\circ}$ 2, 1977, p. 320 (pp. 317-327).

46 Bruno, G., Los Heroicos Furores, Op.cit, p. 31.

47 Véase: Siani, A., "Giordano Bruno: La Poetica degli Eroici Furori», en: O. Catanorchi, O., y Pirillo, D. (ed.): Favole, Metafore, Storie. Seminario su Giordano Bruno, Edizione della Normale (Pisa), pp. 594-595 (pp. 577-599).

${ }_{48}$ Véase el duro pasaje contra el petrarquismo (muy en boga a lo largo de todo el S. XVI) en los Furores: Los Heroicos Furores, Op.cit, pp. 3-6. (véanse también las pp. XXII y XXIII de 
La intrínseca e íntima unión que Bruno realiza del filósofo y el poeta a lo largo de todos los Furores concuerda con otra de las grandes críticas que efectuó en cuanto a la posición del sujeto con respecto a la posesión y el ascenso noético, (y que de hecho está de facto estrechamente ligada a la cuestión del genio poético) que es la que concernía a la ya clásica problemática de la melancolía inspirada y su relación con el furor divino en las artes y en la creación intelectual, relacionándose aquella con los influjos astrológicos de Saturno. Como bien sabemos, esta identificación entre la melancolía saturnina y el genio poético y filosófico fue una confusión que asumió todo el neoplatonismo renacentista a partir de la equivocada atribución de los Problemata del Pseudo-Aristóteles al propio corpus aristotelicum. En esta obra, hoy considerada expurga y datada con posterioridad a la muerte de Alejandro de Afrodisias, se expone, concretamente en la sección XXXII, la conexión directa entre el humor y el temperamento melancólico y una gran aptitud para las artes y las ciencias, o, más directamente, una especial tendencia a recibir el furor y la inspiración divinas. Tanto Ficino como Agripa vieron en este texto la posibilidad de armonizar a Platón y a Aristóteles especialmente en una de las cuestiones más controvertidas en el espectro del furor, la de cómo era posible explicar la conjunción de los humores físicos y los caracteres naturales de las almas derivados de las influencias planetarias con todo el proceso de rapto y purificación en la posesión divina. De hecho, Ficino asumió íntegramente la teoría del Pseudo-Aristóteles y la empleó, en el De amore, para exponer los efectos físicos de los amantes en proceso de enamoramiento, pero simultáneamente, la utilizó en el De triplici vita con un sentido mucho más profundo y destinado a conjugar sus efectos con la teoría del furor divino ${ }^{49}$. Aplicado a este ámbito, Ficino consideró esta melancolía (a la que se le aplicó, por esta conjunción con el furor, el nombre de "inspirada») como un elemento fundamental en la conexión de las partes inferiores y las partes superiores del alma en el proceso de rapto divino; era, por tanto, un estadio más del ascenso noético. De hecho, en el Libro XIII de la Teología platónica, afirmará que una de las formas de liberar el alma del cuerpo es a través de la contracción de la melancolía, que permite la purificación y separación del alma de las cosas externas ${ }^{50}$.

La recepción que Bruno realiza de la problemática de la melancolía inspirada remite esencialmente a su descripción del proceso fisiológica e intelectivamente activo del sujeto furioso, que, en principio, no admitiría el empleo de elementos de posesión auxiliares que, además de erradicar el papel del alma en el acto de furor, no son adquiridos por amor heroico, sino que vienen casi dados de forma innata

la «Introducción»). Sin embargo, Bruno dirá en los diálogos finales que es lícito contemplar la belleza femenina solo si se emplea como medio para contemplar la irradiación de la belleza divina (La contraposición de la Venus terrestre y la Venus celeste de Ficino). Cf. OrdinE, N., Giordano Bruno and the Philosophy of the Ass, Op.cit, p. 159., y El Umbral de la Sombra: Literatura, Filosofía y Pintura en Giordano Bruno, Siruela, 2003, pp. 127-128.

49 Las referencias en el De amore se concentran casi exclusivamente al Cap. IX del sexto discurso (De amore, Op.cit, pp. 142 y 147. El caso del De vita ha sido ampliamente estudiado por D. P. Walker: Spiritual and Demonic Magic from Ficino to Campanella, Penn State Press, 2000, especialmente pp. 4-10.

50 Ficino, M., Teología Platónica, L. XIII, Cap. II, (ed. de Allen, M., y Hankins, J.), Vol. IV, I Tatti Publishing, 2004, p. 163. De hecho, aquí Ficino afirma que los melancólicos son más tendentes por su constitución a la posesión y el furor divinos. 
(ya que a los melancólicos se les consideraba tal por haber nacido bajo el signo astrológico de Saturno). La poesía, por tanto, no puede proceder de una acción melancólica casi profética y depositada en el individuo (que parece remitir de nuevo al hombre como instrumento de la divinidad), sino que ha de manar del intelecto y corazón enfurecidos. No obstante, Bruno en ningún momento negará el verdadero carácter de los melancólicos saturninos, y llegará a afirmar que la melancolía inspirada puede ser un elemento que asista a los espíritus elevados en su ascenso contemplativo, pero nunca un sustitutivo de su capacidad, espíritu y lucidez intelectuales. Está, por tanto, ligada secundariamente a la cognición, pero no es un estadio de la misma ${ }^{51}$. Esta melancolía inspirada, por tanto, guiada como ha de estar por la luz del intelecto y la armonía interna de todas las facultades humanas en comunión con el Todo, debe, en esta inmanencia divina, servir a la ulterior capacidad del genio poético para producir versos místicos y amorosos que, en los límites de lo finito, le permitan consagrarse infinitamente a lo infinito: todo ello, representa, así, la llamada «poética del Infinito».

Universidad Pontificia de Comillas. Madrid

Daniel Ortiz Pereira

[Artículo aprobado para publicación en enero de 2019]

51 Estas afirmaciones las hará principalmente Bruno en el Lampas triginta statuarum (1591) [II, 1-3]. Hay también una referencia temprana en el De compendiosa architectura (1582) [I, 4]. Cf. Catana, L., The Concept of Contraction in Giordano Bruno's Philosophy, Ashgate, 2005, pp. 91-98. 